\title{
Introduction of a new atmospheric pressure plasma device and application on tomato seeds*
}

\author{
Zhuwen Zhou $^{1 \#}$, Yanfen Huang ${ }^{2,3}$, SizeYang ${ }^{4}$, Wei Chen ${ }^{4}$ \\ ${ }^{1}$ Institute of Applied Physics of Guizhou Normal College, Guiyang, China; ${ }^{*}$ Corresponding Author: zhuwenz@gmail.com \\ ${ }^{2}$ Department of Chemistry - Biology Sciences of Guizhou Normal College, Guiyang, China \\ ${ }^{3}$ Horticulture Research Institute, Guizhou Academy of Agricultural Sciences, Guiyang, China \\ ${ }^{4}$ Institute of Physics of Chinese Academy of Sciences, Beijing, China
}

Received 19 August 2010; revised 15 December 2010; accepted 6 January 2011.

\section{ABSTRACT}

We designed new atmospheric pressure plasma device, to explore appropriate voltage of plasma treatment that promote traits and yield of tomato, tomato seeds were treated by plasma at 4760 to $6800 \mathrm{~V}$, and traits and yield of tomato were observed. The results showed that the effects of different voltage plasma treatments on seed germination were not the same. The bloom times, the height, the caulis, the extent of the plants and the average weight, length, diameter of each fruit in the seven treatment groups from 4760 to $6800 \mathrm{~V}$ were increased distinctly. The tomato yields of seven different plasma voltage treated groups were increased than the untreated (CK). In most indexes of our tests, effects of $(5440 \sim 6120 \mathrm{~V})$ plasma voltage treatments were better than of other voltages, the best was $6120 \mathrm{~V}$ plasma voltage treatment. So the tomato yield increase and the most the botany properties of the tomato are improved. The discharges were not uniform and the powers were lower in low voltages $(4760 \sim 5100 \mathrm{~V})$, and the discharge powers were higher in high voltages $(6460 \sim 6800 \mathrm{~V})$. There was a step unaltered violet blue light from $5440 \mathrm{~V}$ to $6120 \mathrm{~V}$, it was nearly uniform discharges, it maybe due to the energy of the electron and the active air particles in the plasma increasing with atmospheric plasma voltage adding, more electric charges are produced per unit time and cannot be neutralized at once, which can strengthen the reaction between the active air particles and seeds. The active air particles and ultraviolet

\footnotetext{
${ }^{*}$ Project supported by the Nature Science Foundation of Guizhou Province Science and Technology Bureau under Grant No J20082101.
}

radiation can penetrate into the capsule of the seeds, accelerate to decompose the inner nutriment of the seeds, reduce relative penetrability of cell velum, improve the activities of the root of the tomato seedling. Test data of fruit yield of the tomato are consistent with the statistical regressive line.

Keywords: Atmospheric Pressure Plasma; Treat Voltage; Tomato Seed; Yield

\section{INTRODUCTION}

Applications of physical technology in agriculture are more and more popular, but most of them are radiations and irradiations with $\gamma$-ray, ${ }^{60} \mathrm{Co}$-ray, laser, electric and magnetic field,[1-13] cells of plant seeds are damaged by radiations.

Plasma has been used in industry for applications; few experimental studies have been carried out for seed mutation induced by atmospheric plasma. We used a atmospheric plasma discharge equipment $[14,15]$ to study the mutations of plant seeds. The device is atmospheric dielectric barrier discharge (DBD) with two parallel high voltage electrodes. A mass of electrons bomb plant seeds and bring much ozone, because seeds were put under atmospherical pressure plasma, the plasma would bring a mass electron, ion and ozone, the mass electron were faster and bomb seeds, the ozone can kill bacterium and virus, and also plant seeds are radiated by ultraviolet-ray, plant seeds are mutated by the many factors. We tested with tomato seeds (No.10 Hongza), to study the effects of atmospheric pressure plasma on the seeds germination, seedling growth, fruit yield and quality of tomato, in order to find the methods of improving the plant growth and increasing fruit yield of tomato. 


\section{EXPERIMENT}

The test device is shown in Figure 1, it is two parallel containers made of quartz, the thickness of quartz is $1 \mathrm{~mm}$, the length is $15 \mathrm{~cm}$, the width is $5 \mathrm{~cm}$, the space of dielectrics is $10 \mathrm{~mm}$. there are some liquid of potassium chloride in two containers, two inner copper rings dipped in the liquid are two electrodes connected to AC high voltage power supply $30 \mathrm{kV}$ with frequency $8 \sim 30$ $\mathrm{kHz}$. Different plant seeds were treated with different plasma voltages, for example, tomato seed for $4760 \sim$ $6800 \mathrm{~V}$, eggplant seed for $4420 \sim 6800 \mathrm{~V}$ [16], cucumber seed for 5610 7310V [15].

As compact joined between the liquid of potassium chloride and dielectrics, both cool quartz dielectrics and uniform plasma were discharged. In our experiment, the tomato seeds were uniformly put on a transmission belt at constant speed, turned on high voltage power supply to discharge, the seeds passed through the plasma, treatment time were controlled by the speed of the belt. There were seven different voltage $(4760,5100,5440$, $5780,6120,6460$ and $6800 \mathrm{~V}$ ) treatments with the same treatment time 6 seconds, the different voltages were produced between two parallel high voltage electrodes and the plasma charges occurred in atmospheric pressure environment, therefore the experiment is called atmospheric dielectric barrier discharge (DBD). The process of treating the seeds by plasma device is shown in Figure 2.

\section{RESULTS AND DISCUSSION}

We designed an atmospheric pressure plasma device. The tomato seeds were treated by different voltage from 4760 to $6800 \mathrm{~V}$. The results showed that the effects of different voltages plasma treatments on seed germination and growth were not the same. The height $(90 \sim 100 \mathrm{~cm})$, the caulis $(>14 \mathrm{~cm})$, the extent $(>55 \times 60 \mathrm{~cm})$ of the plant and the single fruit weight $(>80 \mathrm{~g})$, the length $(\geq 5.2 \mathrm{~cm})$, the diameter $(\geq 5.5 \mathrm{~cm})$ of the tomato of seven treatments from 4760 to $6800 \mathrm{~V}$ were increased distinctly in Table

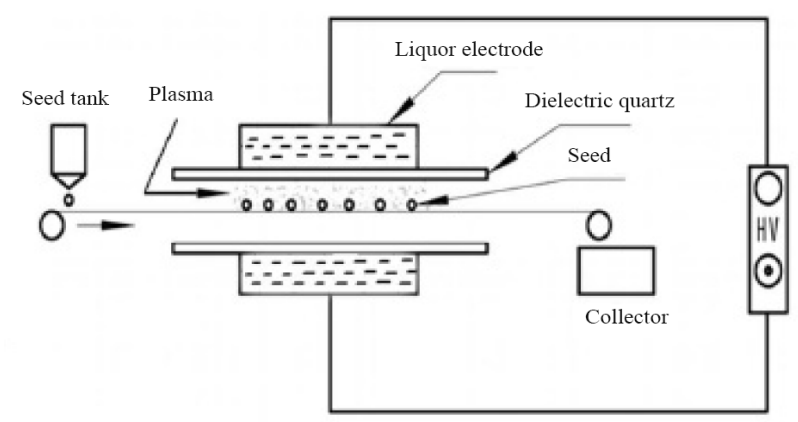

Figure 1. Schematic diagram of the atmospheric plasma dielectric barrier discharge (DBD).

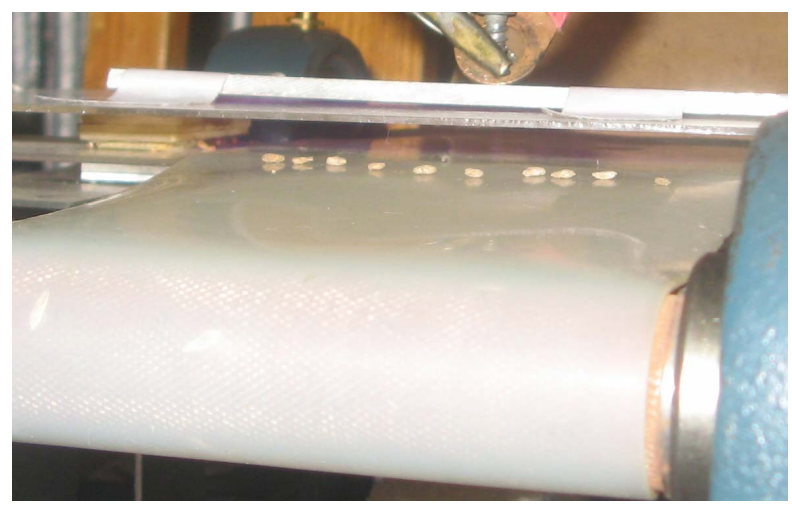

Figure 2. Process of treating seeds by plasma device.

1. In addition, anti-virus of seven treatments (incidence $2.08 \%$ ) were better than the untreated except sixth and seventh treatment (incidence were as same as the untreated $4.17 \%$ ). The bloom times of all the treated seeds were longer and earlier than the untreated (CK), as well as the maturity time (Figure 3). The tomato yields of seven different voltage plasma treatments were increased, the fifth, the fourth and the third treatments were better than the untreated (CK), the yields of the three treatments increased $26.56 \%, 20.31 \%, 16.55 \%$ than CK. In Figure 4 there were obviously increasing yields of the tomato under the proper plasma treatment voltages ranges $(5440 \sim 6800 \mathrm{~V})$, the figure showed that some experimental data compared with Gaussian distribution curve of the fruit yields of the tomato by using a regression line estimate statistical method, the Gaussian distribution curve was regression equation:

$$
y=a \exp \left[-b(x-c)^{2}\right]+d,
$$

here $a=0.743, b=1.500, c=6.120, d=2.797$. The Gaussian distribution curve was comparatively convinced since the $F$-value was calculated: $F=5675>F$ $0.05(1,5)=6.61$, remain standard error: $s=0.02$, it showed that the error was very small between real fruit yields and estimated. In $5440 \sim 6120 \mathrm{~V}$ voltage ranges, the fruit yields were better than other voltages. In most indexes of our tests, the effects of $5440 \sim 6120 \mathrm{~V}$ plasma treatments were better than of other voltages, the best was $6120 \mathrm{~V}$ plasma treatment, real test data of the fruit yields were consistent with the regressive line (estimated yield of forecasting).

Different voltage $(4760 \sim 6800 \mathrm{~V})$ plasma treating the tomato seeds were all better than the untreated (CK) in our experiments, the reasons might be that the treated seeds had been in different physical conditions, the atmospheric pressure plasma device was a dielectric barrier discharge (DBD), it created a typical glow discharge free from filament and arc plasma,[17] the macrotemperature of the plasma was nearly at room tempera- 
Table 1. Change of botany properties of the Tomato treated by different plasma voltage.

\begin{tabular}{ccccccccccccc}
\hline $\begin{array}{c}\text { treat } \\
\text { group }\end{array}$ & $\begin{array}{c}\text { Treat } \\
\text { voltage } \\
(\mathrm{V})\end{array}$ & $\begin{array}{c}\text { Plant height } \\
(\mathrm{cm})\end{array}$ & $\begin{array}{c}\text { Extent } \\
(\mathrm{cm} \times \mathrm{cm})\end{array}$ & $\begin{array}{c}\text { Caulis } \\
\text { height } \\
(\mathrm{cm})\end{array}$ & $\begin{array}{c}\text { Root } \\
\text { length } \\
(\mathrm{cm})\end{array}$ & $\begin{array}{c}\text { Incidence } \\
\text { of virus } \\
(\mathrm{cm})\end{array}$ & $\begin{array}{c}\text { Bloom } \\
\text { time } \\
(\text { day })\end{array}$ & $\begin{array}{c}\text { Fruit } \\
\text { length } \\
(\mathrm{cm})\end{array}$ & $\begin{array}{c}\text { Fruit } \\
\text { diameter } \\
(\mathrm{cm})\end{array}$ & $\begin{array}{c}\text { Fruit } \\
\text { weight } \\
(\mathrm{g})\end{array}$ & $\begin{array}{c}\text { Fruit } \\
\text { yield } \\
\left(\mathrm{kg} / 667 \mathrm{~m}^{2}\right)\end{array}$ & $\begin{array}{c}\text { Increased } \\
\text { yield } \\
(\%)\end{array}$ \\
\hline $\mathrm{CK}$ & 0 & $90-100$ & $55 \times 60$ & 14 & 17.3 & 4.17 & 16 & 5.0 & 5.5 & 80 & 2797 & \\
1 & 4760 & $95-105$ & $60 \times 65$ & 15 & 19.3 & 2.08 & 17 & 5.2 & 5.5 & 85 & 2921 & 4.43 \\
2 & 5100 & $100-110$ & $58 \times 63$ & 15 & 18.7 & 2.08 & 17 & 5.1 & 5.6 & 85 & 2997 & 7.15 \\
3 & 5440 & $100-110$ & $57 \times 60$ & 17 & 19.4 & 2.08 & 17 & 5.0 & 5.7 & 90 & 3260 & 16.55 \\
4 & 5780 & $105-115$ & $55 \times 68$ & 17 & 18.9 & 2.08 & 17 & 5.3 & 5.7 & 100 & 3365 & 20.31 \\
5 & 6120 & $105-115$ & $60 \times 70$ & 17 & 19.4 & 2.08 & 17 & 5.2 & 5.8 & 95 & 3540 & 26.56 \\
6 & 6460 & $100-110$ & $53 \times 64$ & 16 & 20.2 & 4.17 & 17 & 5.0 & 5.6 & 85 & 3142 & 12.33 \\
7 & 6800 & $95-100$ & $56 \times 62$ & 16 & 19.9 & 4.17 & 17 & 5.1 & 5.6 & 90 & 3172 & 13.41 \\
\hline
\end{tabular}

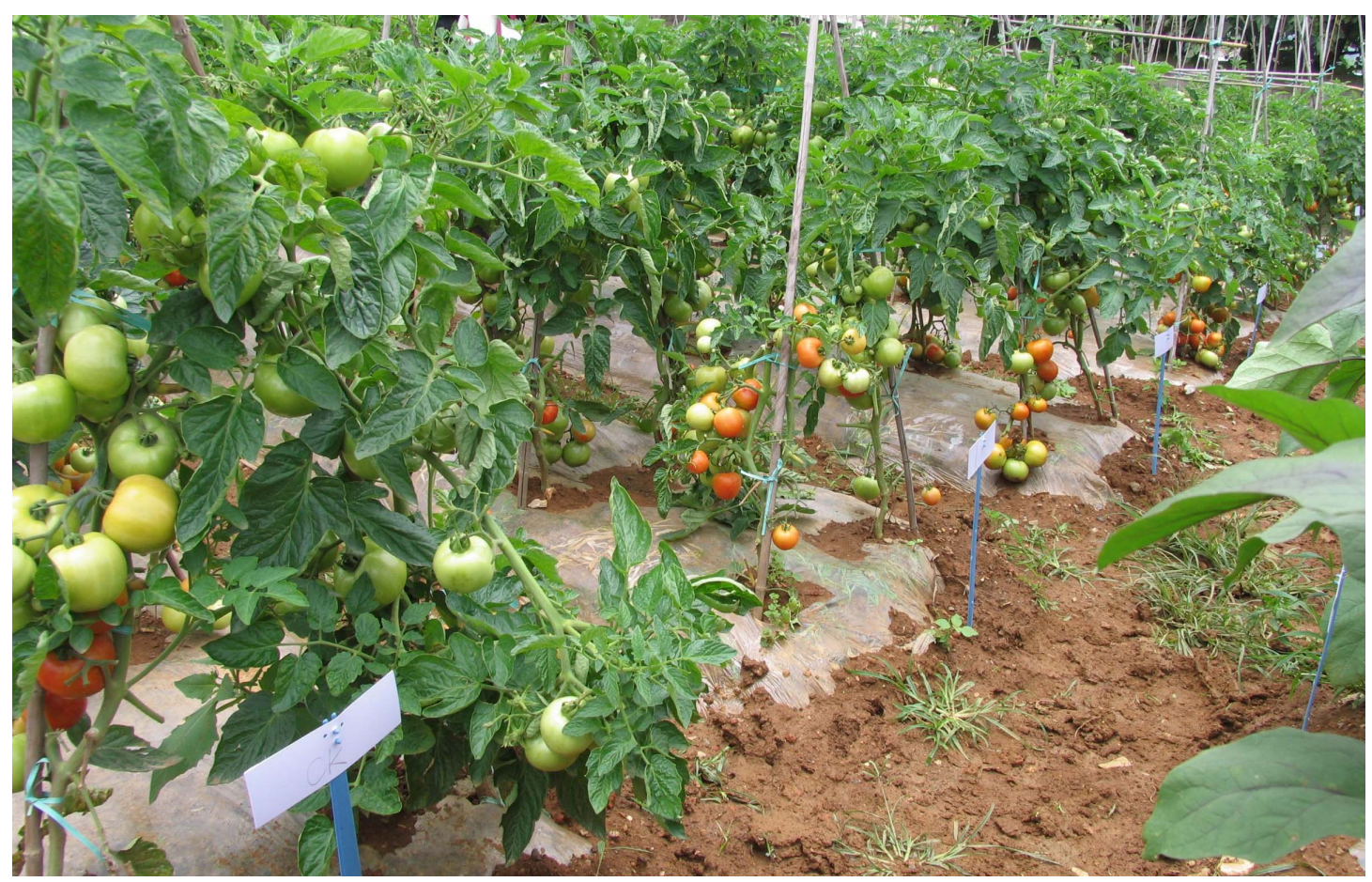

Figure 3. Growth of the tomato plants in the test farmland. The tomato seeds treated by plasma had more fruits than $\mathrm{CK}$, and the treated were premature.

ture, and plasma discharge gas pressure was atmospheric pressure. Because the seeds were passed through the plasma on the transmission belt, the seeds were treated with uniform plasma discharge and were not burned.

In Figure 5 there were seven different discharge processes with seven different voltages, intensity of violet blue light $(350 \mathrm{~nm} \sim 500 \mathrm{~nm})$ gradually increased with voltage adding (see Figure 6), $\mathrm{x}$ axis denoted voltage, and $y$ axis denoted the intensity of violet blue light on Figure 6. The discharges were not uniform using the lower powers in low voltages $(4760 \sim 5100 \mathrm{~V})$, and the higher powers in high voltages $(6460 \sim 6800 \mathrm{~V})$. There was a step unaltered violet blue light from $5440 \mathrm{~V}$ to
$6120 \mathrm{~V}$, it was nearly uniform discharges, it due to the energy of the electron and the active air particles in the plasma increasing with atmospheric plasma voltage adding, more electric charges are produced per unit time and cannot be neutralized at once, which can strengthen the reaction between the active air particles and seeds. The active air particles and ultraviolet radiation can penetrate into the capsule of the seeds, accelerate to decompose the inner nutriment of the seeds, reduce relative penetrability of cell velum, improve the activities of the root of the tomato seedling. Lower voltages $(<5440 \mathrm{~V})$ cannot penetrate into the seeds capsule and higher voltages $(>6120 \mathrm{~V})$ can burnt the inner cells of the seeds. 


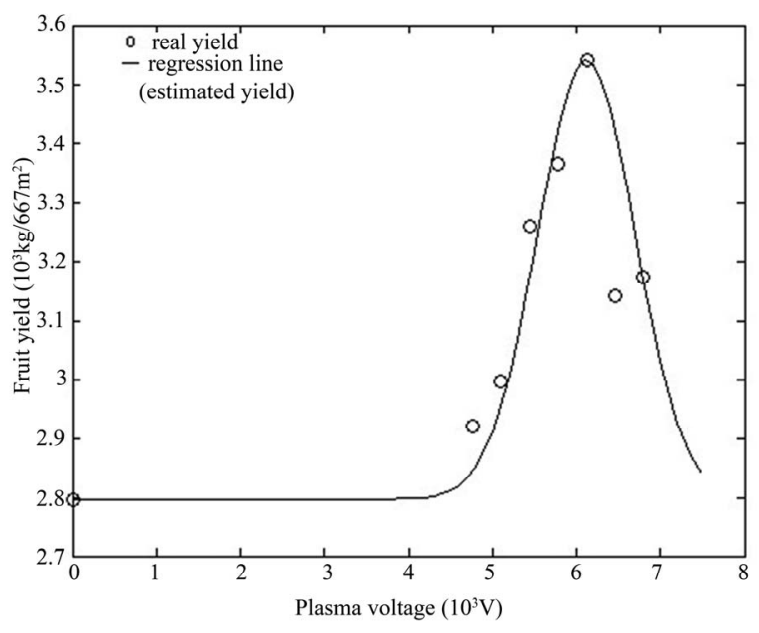

Figure 4. Regression line analysis of fruit yields of tomato. 'o' represents real yield, '- ' represents regression line ( estimated yield of forecasting).

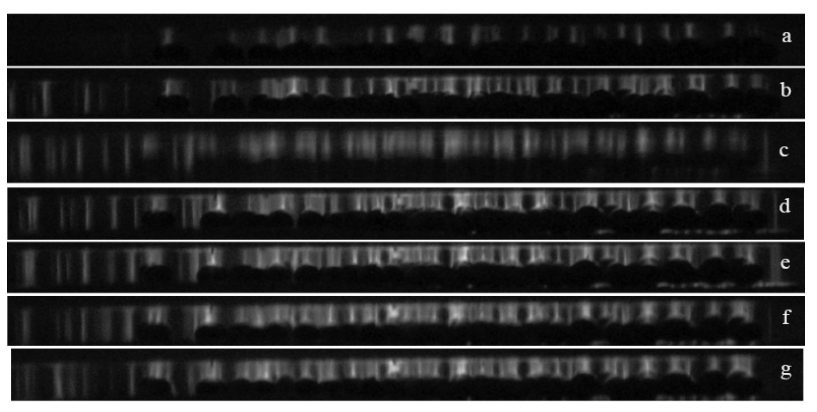

Figure 5. Seven different discharge processes with seven different voltages, intensity of violet blue light gradually increased with adding voltage. In figures $\mathrm{a} \sim \mathrm{b}$ the discharges were not uniform and the powers were lower with low voltages $4760 \sim 5100 \mathrm{~V}$, and the discharge powers were higher with high voltages $6460 \mathrm{~V} \sim 6800 \mathrm{~V}$ in figure $\mathrm{f} \sim \mathrm{g}$. There were uniform discharges under the middle plasma voltages 5440, 5780, and $6120 \mathrm{~V}$ in figures $\mathrm{c}, \mathrm{d}, \mathrm{e}$.

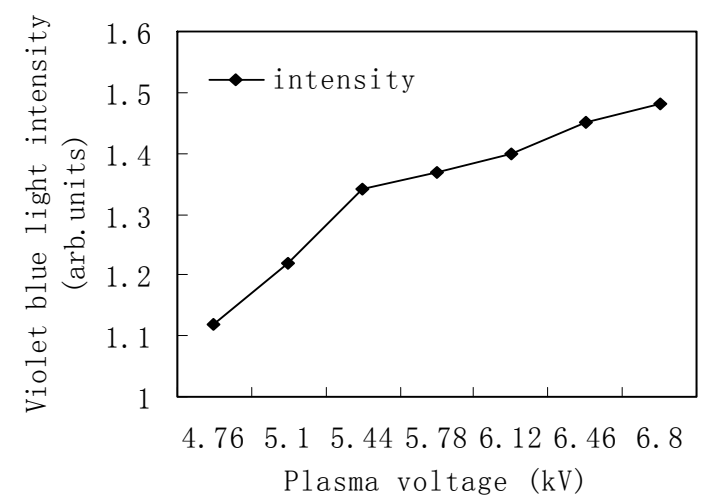

Figure 6. The violet blue light intensity versus different plasma voltage.

For the reasons, the tomato yield increased and the most of the tomato botany properties were improved.

\section{CONCLUSION}

The tomato yields of seven different plasma voltage treated groups were increased than the untreated (CK). In most indexes of our tests, effects of $(5440 \sim 6120 \mathrm{~V})$ plasma voltage treatments were better than of other voltages, the best was $6120 \mathrm{~V}$ plasma voltage treatment. There was a step unaltered violet blue light from 5440V to $6120 \mathrm{~V}$, it was nearly uniform discharges, So the tomato yields increased and the most of the botany properties of the tomato were improved, it due to the energy of the electron and the active air particles in the plasma increasing with atmospheric plasma voltage adding, more electric charges are produced per unit time and cannot be neutralized at once, which can strengthen the reaction between the active air particles and seeds. The active air particles and ultraviolet radiation can penetrate into the capsule of the seeds, accelerate to decompose the inner nutriment of the seeds, reduce relative penetrability of cell velum, improve the activities of the root of the tomato seedling. Test data of fruit yield of the tomato were consistent with the statistical regressive line. In recent research, eggplant seeds were treated by the same method, there were the same conclusion in some aspects.[16, 18,19]

\section{REFERENCES}

[1] Li, H.Z. and Pang, J.A. (2003) Progress of study on seed treatment of physical techniques in cucumber. Agriculture \& Technology, 23, 47-49.

[2] Li, J.W., Sun, Z.K., Yang, S., Zou, Z.Y. and Cong, Y. (1997) A preliminary report on the application of ${ }^{60} \mathrm{CO}-\gamma$ to cucumber mutation breeding. China Vegetables, 22, 22-24.

[3] Wang, Y.H., Han, L.B., Yin, S.X., Liu, G.H. and Chen, $\mathrm{X} . \mathrm{X}$. (2006) The effect of ${ }^{60} \mathrm{CO}-\gamma$ ray irradiation on seeds germination and the activity of enzymes of seeds of Kentucky bluegrass. Chinese Journal of Grassland, 28, 54-57.

[4] Lin, R.R. (1999) Application of magnetic treatment in agriculture. Journal of Fujian Agriculture University, 28, 509-512.

[5] Xiao, W., Wang, Y.L. and Guan, Z.Q. (2004) The effect of magnetized water on seed germination and physiologic norm of balsam pera. Biomagnetism, 4, 7-10.

[6] Wu, X.H., Sun, W.M. and Zhang, H.Y. (2005) Effects of high voltage electrostatic field on biogicalo effect of plant. Heilongjiang Agricultural Sciences, 22, 44-46.

[7] Rajput, M.A. and Qureshi, M.J. (1973) Effect of gamma-irradiation on germination, seedling growth and chlorophyll content in mung bean. Sabrao Newsletter, 5, $39-42$.

[8] Carstensen, E.L. (1997) Biological effects of power frequency electric fields. Journal of Electrostatics, 39, 157-174. doi:10.1016/S0304-3886(97)00003-X 
[9] Souza, T.A., Porras, L.E. and Casate, F.R. (1999) Effect of magnetic treatment of tomato (Lycopersicon esculentum Mill) seeds on germination and seedling growth. Horticultural Abstracts, 70, 6892.

[10] Thimmaiah, S.K., Mahadevu, P. and Srinivasappa, K.N. (1998) Effect of gamma-irradiation on seed germination and seedling vigour in cowpea [vigna unguiculata (L.) walp]. Journal of Nuclear Agriculture and Biology, 27, 142-145.

[11] Garcia, R.F. and Arza, P.L. (2001) Influence of a stationary magnetic field on water relations in lettuce seeds. Part I: Theoretical consideration smagnetics. Bioelectromagnetics, 22, 589-595. doi:10.1002/bem.88

[12] Xia, L.H., Yi, Y.L., Liu, X.Y. and Liu, J. (1999) Study on effect of magnetic field on cucumber seed. Journal of Shenyang Agriculture University, 30, 24-26.

[13] Chen, J.G., Jin, Z. and Li, S.H. (1995) The development of the nonvacuum pulsh electronic beam appartus and its mutagenic effects on pea seeds. Journal of Nuclear Agriculture, 9, 7-9.

[14] Wang, M., Chen, Q.Y., Chen, G.L. and Yang, S.Z. (2007) Effect of atmospheric pressure plasma on growth and development of lettuce. ACTA Agricultural Boreali-Sinica, 22, 108-113.

[15] Wang, M., Yang, S.Z., Chen, Q.Y., Gao, L.H., Chen, G.L. and Liu, X.J. (2007) Effects of atmospheric pressure plasma on seed germination and seedling growth of cucumber. Transactions of the CSAE, 23, 195-200.

[16] Zhou, Z.W., Huang, Y.F., Deng, M.S. and Yang, S.Z. (2010) Effects of eggplant seed treatment with atmospheric pressure plasma on plant growth and yield. China Vegetables, 207, 62-66.

[17] Chen, G.L., Fan, S.H., Li, C.L., Gu, W.C., Feng, W.R. and Yang, S.Z. (2005) A novel atmospheric pressure plasma fluidized bed and it $\mathrm{s}$ application in mutation of plant seed. Chinese Physics Letters, 22, 1980-1983. doi:10.1088/0256-307X/22/8/044

[18] Zhou, Z.W., Huang, Y.F., Deng, M.S. and Yang, S.Z. (2009) Effects of atmospheric pressure plasma to the eggplant seed on the eggplant yield and quality. Modern Agricultural Sci-Tech, 19, 94-96.

[19] Huang, Y.F. and Zhou, Z.W. (2010) Applied effect of atmospheric pressure plasma technology to eggplant. Seed, 29, 73-75. 